\title{
Comparison of different locking plate fixation methods in distal tibia fractures
}

\author{
Krzysztof Piątkowski $^{1}$ (i) - Piotr Piekarczyk ${ }^{1} \cdot$ Krzysztof Kwiatkowski $^{1}$ • \\ Mateusz Przybycień ${ }^{1} \cdot$ Bartlomiej Chwedczuk $^{1}$
}

Received: 6 May 2015 / Accepted: 24 June 2015 /Published online: 15 July 2015

(C) The Author(s) 2015. This article is published with open access at Springerlink.com

\begin{abstract}
Purpose The aim of our study was to assess the outcome of locking plate fixation of distal tibia fractures and evaluate which surgical approach and method of plate fixation is related to better functional result and lower complication rate. Methods A retrospective analysis of treatment of 45 patients was made. Patients were divided into two subgroups regarding surgical approach (medial vs anterior) and fixation method (bridge plating vs rigid fixation). Time from injury to full bone union was noted, and clinical outcome was assessed by AOFAS score.

Results Nonunion was the most prevalent complication and was observed in $26.6 \%$ of patients. Infection rate was $11.1 \%$. Higher rate of bone union complications was noted in the anterior approach group with anterolateral anatomical plate. Infection and re-operation rates were similar in all subgroups. There were no correlations between fracture extension, length of plate and screw placement with bone healing time and AOFAS score.

Conclusions Outcome of plate fixation of distal tibia fracture did not depend on the fixation method or surgical approach but, when possible, the medial plating via MIPO technique is a favourable method of treatment.
\end{abstract}

Keywords Tibia $\cdot$ Fracture fixation $\cdot$ Locking plate $\cdot$ Bone healing

Krzysztof Piątkowski

krzpia@gmail.com

1 Department of Traumatology and Orthopaedics, Military Institute of Medicine, Szaserów str. 128, 04-141 Warsaw, Poland

\section{Introduction}

Distal tibia fractures are commonly known among orthopaedic surgeons as "pilon" fractures [1]. This term comes from the French word "pestle", and was used by anatomist and radiologist Étienne Destot [2]. He compared the anatomy of ankle joint to mortar and pestle, where the trochlea plays the role of a pestle, and the distal ends of tibia and fibula are mortar. A hit directed axially, like during fall from height, causes fracture of distal tibia.

In general, outcome after treatment of pilon fractures is still unsatisfactory. Skin and soft tissue healing complications, delayed union, nonunion, or infection are rather common. It is mainly due to anatomical conditions of this area, which has a poor blood supply and thin soft tissue coverage. Another reason is that those fractures are often caused by high-energy injuries, frequently are open, with massive contusion of skin, muscles and blood vessels [3]. Moreover after surgical treatment of pilon fractures development of arthritis can be observed even in two-third of cases [4]. It is now postulated that surgical treatment should be held in stages according to the rules of damage control orthopaedics. Moreover, development of implants with angular stability and less invasive stabilization techniques gives us hope of acquiring better mid- and long-term results [5-7].

The aim of this study was to assess the outcomes of distal tibia fractures treatment with use of different types of plate fixation. Nowadays many kinds of pre-bent (anatomical) locking plates for distal tibia are available, but there are no clear guidelines stating which surgical approach, type of plate, or method of bone fragments fixation should be used. In this study we wanted to check whether type of fracture, type of fixation plate, length of fixation plate, and use of interfragmentary lag screws has any influence on outcome of surgical treatment and prevalence of complications. 

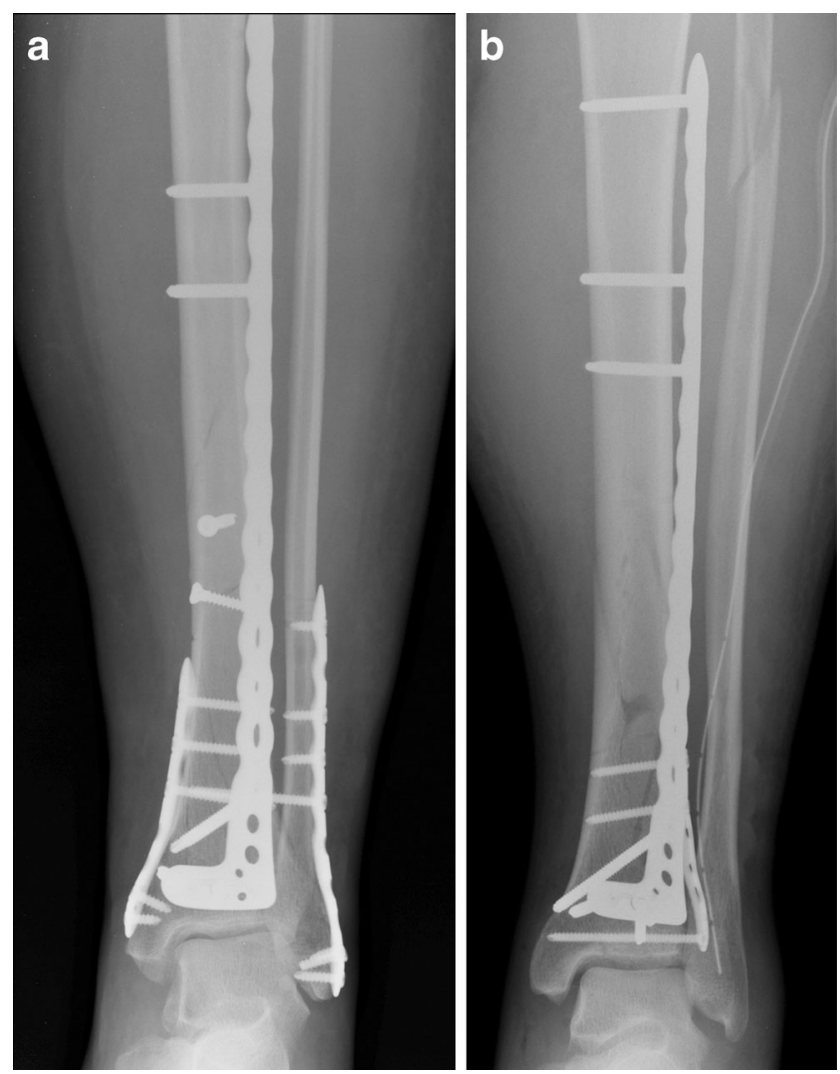

Fig. 1 a Post-operative, AP X-ray of a patient aged 45 years after AO 43$\mathrm{C} 1$ fracture treated with anatomical anterolateral locking plate fixation with additional lag screws (rigid fixation). b Post-operative, AP X-ray of a patient aged 51 years after $\mathrm{AO} 43-\mathrm{C} 3$ fracture treated with anatomical anterolateral locking plate fixation without use of lag screws

\section{Materials and methods}

A retrospective analysis of treatment of patients with distal tibia fractures treated at a Level 1 Trauma Centre was conducted. For this study we qualified patients with extra-articular fractures (AO 43-A) up to $4 \mathrm{~cm}$ from the articular surface, and patients with intra-articular fractures (AO 43-B and C). A total of 45 patients, who underwent all follow-up ambulatory examinations, were qualified for this study. Length of fracture was measured on pre-operative radiographs by taking the distance from the proximal end of fracture line to the ankle joint. Length of used fixation plate and distance from proximal end of fracture to the first screw in diaphyseal part of the fixation plate was measured using post-operative radiographs (Fig. 1a, b).

Time to bone union was determined using post-operative radiographs taken six weeks after operation and then after two, four, six and nine months. When union appeared, time in weeks that elapsed from operative treatment was noted. It was done separately for lateral malleolus and for tibia. Lack of visible bone union after six months was regarded as delayed union. When there was no union after 12 months (non-union) patients were qualified for reoperation. Angular deformity $>5^{\circ}$ visible on antero-posterior or lateral views was regarded as axial deformation of extremity. Implant loosening or breaking, and development of post traumatic arthritis of ankle joint were also assessed using post-operative radiographs.

Clinical examination was held at least one year after surgery. Pain was measured using VAS (visual analog scale) score. Patients in presence of an independent investigator filled out an AOFAS (American Orthopaedic Foot and Ankle Society) questionnaire [8]. AOFAS scale results up to 69 points were deemed as bad, from 70 to 79 points as acceptable, from 80 to 89 points as good and above 89 points as excellent.

Patients were divided into subgroups according to type of fracture, surgical approach and type of fixation (Table 1). Rate of complications of bone healing (delayed union and nonunion) and surgical site infections were assessed for each subgroup. Moreover, length of fracture, length of plate and distance from proximal end of fracture to first diaphyseal screw were compared with time to bone union, presence and size of callus and achieved functional outcome in AOFAS scale. Statistical analyses were made with MS Excel software with Analysis ToolPak plug-in. Comparison of achieved results in each subgroup was made with Student's 2-sided $t$ test. Nonparametric assessment of complication rate in each subgroup was made with 2-sided Fisher's exact test.

\section{Results}

The investigated group consisted of 45 patients (20 female and 25 male). Mean age was 49 years (20-84 years). Mean

Table 1 Subgroups distribution

\begin{tabular}{|c|c|c|c|c|}
\hline Subgroups & Surgical approach & Type of fixation plate & Use of interfragmentary lag screws & Number of patients \\
\hline $\begin{array}{l}\text { Group I } \\
\text { Medial plate }\end{array}$ & Medial approach & $\begin{array}{l}\text { Medial plate placed with } \\
\text { MIPO technique }\end{array}$ & - & 12 \\
\hline $\begin{array}{l}\text { Group II } \\
\text { Antero-lateral plate }\end{array}$ & $\begin{array}{l}\text { Anterior, or antero- } \\
\text { lateral approach }\end{array}$ & Antero-lateral plate & - & 32 \\
\hline $\begin{array}{l}\text { Group A } \\
\text { Flexible fixation }\end{array}$ & - & - & $\mathrm{NO}$ & 14 \\
\hline $\begin{array}{l}\text { Group B } \\
\text { Rigid fixation }\end{array}$ & - & - & YES & 27 \\
\hline
\end{tabular}


time of hospitalisation was eight days and mean time from admission to surgery was five days. Most fractures were intraarticular (26 cases; $58 \%$ ). According to AO classification there were 19 type 43-A fractures, 7 type 43-B fractures and 19 type 43-C fractures.

Overall mean functional result according to AOFAS score was 77 points (from $35-100$ points, median 80 points). Excellent results were noted in $22.2 \%$ ( 10 of 45 ) patients, good in $31.1 \%$ (14 of 45) patients, acceptable in $20 \%$ ( 9 of 45 ) patients and bad in $26.7 \%$ (12 of 45 ) patients. Mean time to bone union of tibia was 19 weeks, while mean time to bone union of lateral malleolus, in cases when it was also broken, was shorter, namely, 16 weeks. Re-operation, regardless of reason, was required in one third of cases (15 out of 45 patients, $33.3 \%$ ). Delayed union and non-union was observed in 18 patients $(40 \%)$. Non-union that required re-operation was noted in 12 patients $(26.6 \%)$. Deformities of shin axis were noted in six patients $(13.3 \%)$. Most of them were valgus deformity (five out of six patients, $83.3 \%$ ), and only one case of varus deformity was noted. Late infection, reaching the metal implant, that required admission and treatment at the septic ward was noted in five patients $(11.1 \%)$.

There was no correlation between length of fracture, length of plate and distance from proximal end of fracture to first diaphyseal screw and results of treatment in AOFAS score. Positive correlation between length of plate with time to bone union was noted ( $p<0.05$, Pearson correlation coefficient), but there was no significant correlation between length of fracture and distance from fracture to first diaphyseal screw $(p>0.05$, Pearson correlation coefficient).

In extraarticular fractures (AO 43-A) rigid fixation with plate and lag screws was used more often (group B). In intraarticular fractures AO type 43-C, fixation with flexible bridge plating, was the most frequently used method (group A). The anterior approach and fixation with antero-lateral plate was the most frequent choice (group II). Most cases, when the medial approach was used, were in patients with extra-articular fracture.

\section{Results according to type of fracture}

Functional results according to AOFAS score were similar in all three types of fracture. Mean result in AO type 43-A fractures was 75 points, in group with $\mathrm{AO}$ type 43 -B fracture it was 78 points and in $\mathrm{AO}$ type $43-\mathrm{C}$ it was 79 points. Mean time to bone union (including those patients that required reoperation due to non-union) was accordingly 19, 13 and 23 weeks.

Rate of deep surgical site infections was highest in group of patients with extraarticular fractures AO type 43-A and it reached $21.1 \%$. Rate of surgical site infections and nonunions was slightly lower in $\mathrm{AO}$ type 43-B fractures which 
involve only epiphysis and metaphysis of tibia. Nevertheless when both types of intra-articular fractures AO type 43-B and 43-C were compared to extra-articular AO type 43-A fractures, no statistically significant differences were found in prevalence of surgical site infections ( $p>0.1$, Fisher's exact test), or bone healing disorders of tibia $(p>0.1$, Fisher exact test). Re-operation rate was similar in all types of fractures and it was approximately $30 \%$. Results of treatment according to type of fracture are presented in Table 2.

\section{Results according to surgical approach (groups I and II)}

It should be noted that group I consisted mostly of extra-articular, AO 43-A type fractures (66.7 \%). In both groups mean functional result according to AOFAS score was similar and it was 77 points in group I and 78 points in group II ( $p>0.1$, Student's two-sided $t$ test). Pain level measured with VAS scale was similar in both groups $(p>0.1)$. Time to bone union was different at 16 and 22 weeks in groups I and II, respectively ( $p=0.053$, Student's two-sided $t$ test). Problems with bone union (delayed union as well as non-union that required reoperation) were more often in group II $(p=0.08)$. Rate of infection was similar in both groups, accordingly 13 and $11 \%$
( $p>0.1$ Fisher exact test). There were no differences in reoperation rate and in rate of postoperative angular deformity of shin and ankle joint. Full data comparison is found in Table 3.

\section{Results according to type of fixation (groups A and $B$ )}

In 14 cases of multifragmentary fracture, flexible bridge plating fixation without lag screws was chosen (group A), and in 27 cases patients were treated with rigid fixation with use of plate with angular stability and lag screws (group B).

There were no statistically significant differences in prevalence of complications in both groups. Nevertheless, it is worth noticing that patients from group A had slightly better functional results in AOFAS score than patients from group B ( 82 points vs 75 points, $p=0.21$, Student's two-sided $t$ test). Patients with flexible fixation without any lag screws required more time to achieve bone union (accordingly 21 weeks vs 19 weeks, $p=0.49$, Student's two-sided $t$ test). What is understandable in the group with flexible fixation is that more angular deformities were noticed $(21.4 \%$ vs $11.1 \%, p=0.39$, Fisher's exact

Table 3 Comparison of results according to surgical approach and fixation plate

\begin{tabular}{|c|c|c|c|}
\hline Results & Group I (medial approach), N=12 & Group II (anterior approach), N=32 & $P$-value \\
\hline Age (SD) & $49(17.1)$ & $48(12.7)$ & 0.89 \\
\hline \multicolumn{4}{|l|}{$\operatorname{Sex}(\%)$} \\
\hline Male & $3(25 \%)$ & $22(68.8 \%)$ & \\
\hline Female & $9(75 \%)$ & $10(31.2 \%)$ & \\
\hline \multicolumn{4}{|l|}{ Lateral malleolus fracture (\%) } \\
\hline No fracture & $6(50 \%)$ & $7(21.9 \%)$ & \\
\hline Type A according to D-W & $1(8.3 \%)$ & $0(0 \%)$ & \\
\hline Type B according to D-W & $2(16.6 \%)$ & $10(31.2 \%)$ & \\
\hline Type $\mathrm{C}$ according to $\mathrm{D}-\mathrm{W}$ & $3(25 \%)$ & $15(46.9 \%)$ & \\
\hline \multicolumn{4}{|l|}{ Types of fracture (AO) (\%) } \\
\hline Type A & $8(66.7 \%)$ & $11(34.4 \%)$ & \\
\hline Type B & $3(25 \%)$ & $3(9.4 \%)$ & \\
\hline Type C & $1(8.3 \%)$ & $18(56.3 \%)$ & \\
\hline Time to fracture union (SD) & $16(8.5)$ & $22(5.6)$ & 0.053 \\
\hline Reoperation rate $(\%)$ & $4(33.3 \%)$ & $11(34.4 \%)$ & 1.0 \\
\hline Bone Union complications (\%) & $2(16.6 \%)$ & $16(50 \%)$ & 0.08 \\
\hline Delayed Union (\%) & $0(0 \%)$ & $6(18.6 \%)$ & 0.31 \\
\hline Non-union with reoperation (\%) & $2(16.6 \%)$ & $10(31.2 \%)$ & 0.46 \\
\hline Infection $(\%)$ & $1(11 \%)$ & $4(12.9 \%)$ & 1.0 \\
\hline Mean AOFAS value (SD) & $77(13.6)$ & $75(16.3)$ & 0.87 \\
\hline Mean pain level in VAS scale (SD) & $2(1.9)$ & $2(1.6)$ & 0.83 \\
\hline Angular deformity $>5^{\circ}(\%)$ & $1(11 \%)$ & $5(15.6 \%)$ & 1.0 \\
\hline
\end{tabular}


test). There were no differences in rate of bone union disorders and in rate of infections in both groups. Full data comparison is found in Table 4.

\section{Discussion}

Taking into consideration rate of complications presented in this investigation we must underline that population of patients, who continued treatment and were present at all follow-up ambulatory check-ups, might not be representative due to the fact that patients who experienced serious complications that required re-operation are more eager to continue their treatment than those without any complaints. Thus higher prevalence of non-union and surgical site infection might be overestimated. In the literature, rate of those complications in patients with pilon type fracture is also high. Rate of infection varies depending on author from 5 to $37 \%$ and rate bone union disorders often exceeds $20 \%$ [5, 9-11].

In surgical treatment of fractures of distal tibia, proper choosing of approach plays a very important role. A wellplanned and executed approach enables the surgeon to perform good fracture reposition as well as determines which type of fixation plate might be used. The most popular is the antero-lateral approach [12]. It allows proper exposition of lateral malleolus and distal tibia, especially its epiphysis [13]. With this approach precontoured, antero-lateral plate should be used for fixation of tibia fracture. Properly placed plate in this region is well covered with soft tissue, thus minimizing risk of problems with surgical wound healing. A possible complication in this approach is iatrogenic rupture of superficial peroneal nerve that is localized in this area.

In case of extra-articular fractures, or fractures with the main fragment localized on the medial part of distal tibia, the medial approach with use of medial pre-bent plate placed with the MIPO technique should be used. This approach does not allow proper exposure of fracture on the antero-lateral side of the distal tibia (Tillaux-Chaput fracture), and thus should not be used as a single approach in comminuted intra-articular fractures. Contraindication to this method is poor condition of skin and soft tissue in the area of the medial malleolus. A thin layer of soft tissue covering this place increases risk of having problems with wound healing above the plate, which may lead to greater number of surgical site infections. Moreover, when risk factors such as diabetes, arteriosclerosis of lower extremities, or smoking are present, then risk of infection is also much higher [14].

From a mechanical point of view it seems that fixation with a medial plate, as well as with antero-lateral plate, gives a comparable level of stability. Yenna et al. [15], in their

Table 4 Comparison of results according to fixation method (bridge plating vs rigid fixation)

\begin{tabular}{|c|c|c|c|}
\hline Results & Group A (bridge plating) $\mathrm{N}=14$ & Group B (rigid fixation) $N=27$ & $P$-value \\
\hline Age (SD) & $51(13.1)$ & $48(14.4)$ & 0.89 \\
\hline \multicolumn{4}{|l|}{ Sex } \\
\hline Male & $7(50 \%)$ & $17(37 \%)$ & \\
\hline Female & $7(50 \%)$ & $10(63 \%)$ & \\
\hline \multicolumn{4}{|l|}{ Lateral malleolus fracture (\%) } \\
\hline No fracture & $2(14.3 \%)$ & $11(40.7 \%)$ & \\
\hline Type A according to D-W & $0(\%)$ & $1(3.7 \%)$ & \\
\hline Type B according to D-W & $4(28.6 \%)$ & $6(22.2 \%)$ & \\
\hline Type $\mathrm{C}$ according to $\mathrm{D}-\mathrm{W}$ & $8(57.1 \%)$ & $9(33.3 \%)$ & \\
\hline \multicolumn{4}{|l|}{ Types of fracture (AO) (\%) } \\
\hline Type A & $4(28.6 \%)$ & $15(55.6 \%)$ & \\
\hline Type B & $1(7.1 \%)$ & $4(14.8 \%)$ & \\
\hline Type C & $9(64.3 \%)$ & $8(29.6 \%)$ & \\
\hline Time to fracture union (SD) & $21(7.6)$ & $19(8.2)$ & 0.49 \\
\hline Reoperation rate $(\%)$ & $3(21.4 \%)$ & $10(37 \%)$ & 0.48 \\
\hline Bone union complications (\%) & $6(42.8 \%)$ & $11(40.7 \%)$ & 1.0 \\
\hline Delayed union (\%) & $2(14.3 \%)$ & $4(14.8 \%)$ & 1.0 \\
\hline Non-union with reoperation (\%) & $4(28.6 \%)$ & $7(25.9 \%)$ & 1.0 \\
\hline Infection $(\%)$ & $1(7.1 \%)$ & $4(14.8 \%)$ & 0.65 \\
\hline Mean AOFAS value (SD) & $82(11.8)$ & $75(17.3)$ & 0.21 \\
\hline Mean pain level in VAS scale (SD) & $2(1.9)$ & $2(1.8)$ & 0.83 \\
\hline Angular deformity $>5^{\circ}(\%)$ & $3(21.4 \%)$ & $3(11.1 \%)$ & 0.39 \\
\hline
\end{tabular}


research on anatomical models of distal tibia fractures from 2011, did not find any differences in strength of medial, or antero-lateral plate fixation, but there are no reports of clinical studies that would prove this statement.

Lee et al., in 2009, compared fixation with plates placed on medial or lateral sides of tibia. This research showed a slight advantage of fixation with the lateral plate. In cases of medial plates, incidence of surgical site infections was higher $(p=0.047)$, and patients more often complained of pain caused by implant localized in close proximity to the skin $(p<0.001)$ [9]. In our research there was no evidence that would sustain those statements. Similar incidence of surgical site infections was found in both subgroups treated with either medial, or antero-lateral plate. We believe that prevalence of infections depends mainly on the extent of injury, contusion of soft tissue, as well as on patients' individual risk factors.

In our analysis we showed that time to bone union was shorter in the group treated with medial plate $(p=0.053)$. Moreover, problems with bone healing were more often when antero-lateral plate was used $(p=0.08)$. Those differences are noticeable but none of them is statistically significant $(p>0.05)$. Also the fact that investigated groups were highly diversified when it comes to extent of injury should be taken under consideration. Most patients (18 out of 19) with highenergy, comminuted fractures type 43-C, were treated with antero-lateral plate. It might be that high rate of problems with bone union in this group was related not only to type of surgical approach and plate used, but also to energy and extent of injury. To sum up, factors that have influence on choice of approach and type of fixation in pilon fractures are type of fracture and condition of soft tissue [16, 17].

Analysing subgroups according to rigidity of fixation and usage of lag screws we found that slightly better functional results measured with AOFAS score were found in the group treated with bridging plate ( 82 points vs 75 points). No differences in time to bone union, or prevalence of complications were observed. Hasenboehler et al. [18], in 2007, showed good results of treatment of distal tibia fractures with medial plates using the MIPO technique with interfragmentary lag screws (rigid fixation). The authors stated that to avoid the risk of prolonged secondary bone healing and plate bending complications in fractures 43-A and 43C1-C2 interfragmentary compression is needed. Horn et al. [19], in a study from 2011, found that results of treatment with rigid fixation, or with bridging plate are similar, but patients with interfragmentary screws were allowed full weight bearing earlier (around 11 weeks) than patients with bridging plates (around 15 weeks). Mass of callus was smaller in cases of rigid fixation with use of lag screws. In our study the majority of patients $(55.6 \%)$ with extraarticular fractures $43-\mathrm{A}$ were treated with interfragmentary screws and most patients
$(64.3 \%)$ with mulitifragmentary intraarticular fractures $43-\mathrm{C}$ were treated with bridging plate techinique. Because of this asymmetry regarding group assignment the comparative study is not realiable.

\section{Conclusions}

Higher prevalence of problems with bone union was found after use of antero-lateral plate placed from an anterior, or antero-lateral approach, but those results are not statistically significant $(p=0.053)$. Type of plate, or surgical approach does not influence infection rate after surgical treatment of pilon fractures. The resultss of treatment with bridging plate and with rigid fixation with interfragmentary screws were comparable.

Due to high rate of problems with bone union, in order to minimise its risk, it is advisable to use a medial approach and MIPO fixation technique whenever there are no contraindications for this method. In most cases of comminuted, intraarticular fractures of distal tibia, when it is impossible to use MIPO techniques, choice of surgical approach should be based on fracture pattern, condition of soft tissue and general patient risk factors.

Acknowledgments The publication was prepared within the framework of the research program of the Ministry of Defence of Republic of Poland No. 16/WNiI/2007.

Conflict of interest The authors declare that they have no competing interests.

Open Access This article is distributed under the terms of the Creative Commons Attribution 4.0 International License (http:// creativecommons.org/licenses/by/4.0/), which permits unrestricted use, distribution, and reproduction in any medium, provided you give appropriate credit to the original author(s) and the source, provide a link to the Creative Commons license, and indicate if changes were made.

\section{References}

1. Michelson J, Moskovitz P, Labropoulos P (2004) The nomenclature for intra-articular vertical impact fractures of the tibial plafond: pilon versus pylon. Foot Ankle Int 25:149-150

2. Mandi DM, Belin RP, Banks J, Barrett B (2012) Pilon fractures. Clin Podiatr Med Surg 29(2):243-278. doi:10.1016/j.cpm.2012.01. 001

3. McFerran MA, Smith SW, Boulas HJ, Schwartz HS (1992) Complication encountered in the treatment of pilon fractures. J Orthop Trauma 6(2):195-200

4. Cesari B, Lortat-Jacob A, Dinh A, Katabi M, Decrette E, Benoit J (1996) Fractures of the anterior rim of the distal part of the tibia. Apropos of a series of 38 cases. Rev Chir Orthop Reparatrice Appar Mot 82(5):417-427

5. Calori GM, Tagliabue L, Mazza E, de Bellis U, Pierannunzii L, Marelli BM, Colombo M, Albisetti W (2010) Tibial pilon fractures: 
which method of treatment? Injury 41(11):1183-1190. doi:10. 1016/j.injury.2010.08.041

6. Bastias C, Henríquez H, Pellegrini M, Rammelt S, Cuchacovich N, Lagos L, Carcuro G (2014) Are locking plates better than nonlocking plates for treating distal tibial fractures? Foot Ankle Surg 20(2):115-119. doi:10.1016/j.fas.2013.12.004

7. Ketz J, Sanders R (2012) Staged posterior tibial plating for the treatment of Orthopaedic Trauma Association 43C2 and 43C 3 tibial pilonfractures. J Orthop Trauma 26(6):341-347. doi:10.1097/BOT. 0b013e318225881a

8. Kitaoka HB, Alexander IJ, Adelaar RS, Nunley JA, Myerson MS, Sanders M (1994) Clinical rating systems for the ankle-hindfoot, midfoot, hallux, and lesser toes. Foot Ankle Int 15(7):349-353

9. Lee YS, Chen SH, Lin JC, Chen YO, Huang CR, Cheng CY (2009) Surgical treatment of distal tibia fractures: a comparison of medial and lateral plating. Orthopedics 32(3):163

10. Teeny SM, Wiss DA (1993) Open reduction and internal fixation of tibial plafond fractures. Variables contributing to poor results and complications. Clin Orthop Relat Res 292:108-117

11. Danoff JR, Saifi C, Goodspeed DC, Reid JS (2014) Outcome of 28 open pilon fractures with injury severity-based fixation. Eur J Orthop Surg Traumatol 25(3):569-575. doi:10.1007/s00590-0141552-7

12. Hak DJ (2012) Anterolateral approach for tibial pilon fractures. Orthopedics 35(2):131-133. doi:10.3928/01477447-20120123-31

13. Mehta S, Gardner MJ, Barei DP, Benirschke SK, Nork SE (2011) Reduction strategies through the anterolateral exposure for fixation of type B and C pilon fractures. J Orthop Trauma 25(2):116-122. doi:10.1097/BOT.0b013e3181cf00f3

14. Kline AJ, Gruen GS, Pape HC, Tarkin IS, Irrgang JJ, Wukich DK (2009) Early complications following the operative treatment of pilon fractures with and without diabetes. Foot Ankle Int 30(11): 1042-1047. doi:10.3113/FAI.2009.1042

15. Yenna ZC, Bhadra AK, Ojike NI, ShahulHameed A, Burden RL, Voor MJ, Roberts CS (2011) Anterolateral and medial locking plate stiffness in distal tibial fracture model. Foot Ankle Int 32(6):630 637. doi:10.3113/FAI.2011.0630

16. Shon OJ, Park CH (2012) Minimally invasive plate osteosynthesis of distal tibial fractures: a comparison of medial and lateral plating. J Orthop Sci 17(5):562-566. doi:10.1007/s00776-012-0241-9

17. Encinas-Ullán CA, Fernandez-Fernandez R, Rubio-Suárez JC, GilGaray E (2013) Medial versus lateral plating in distal tibial fractures: a prospective study of 40 fractures. Rev Esp Cir Ortop Traumatol 57(2):117-122. doi:10.1016/j.recot.2012.11.004

18. Hasenboehler E, Rikli D, Babst R (2007) Locking compression plate with minimally invasive plate osteosynthesis in diaphyseal and distal tibial fracture: a retrospective study of 32 patients. Injury 38(3):365-370

19. Horn C, Döbele S, Vester H, Schäffler A, Lucke M, Stöckle U (2011) Combination of interfragmentary screws and locking plates in distal meta-diaphyseal fractures of the tibia: a retrospective, single-centre pilot study. Injury 42(10):1031-1037. doi:10.1016/j. injury.2011.05.010 